\title{
Potential Inter-Fuel Substitution between Hydroelectricity and Fossil Fuels in Nepal
}

\author{
Sudheer Awasthi ${ }^{1}$ and Naveen Adhikari ${ }^{2}$ \\ ${ }^{1} \mathrm{Mr}$. Awasthi is a researcher at Shodhashala-Center for Research and Policy Studies, \\ Baluwatar, Kathmandu. Email: awa.sudheer@gmail.com
}

${ }^{2}$ Corresponding author. Mr. Adhikari is Assistant Professor at Central Department of Economics, Tribhuvan University, Kirtipur, Kathmandu. Email: nabueco@gmail.com

\begin{abstract}
In spite of huge hydro-electricity potential, Nepal still relies on fossil fuel to meet its energy demand. However, as the pace of hydroelectricity generation gets momentum in recent years, there are concerns about the excess supply of hydroelectricity in the domestic market in the near future. In this context, this paper examines the potential substitution of conventional fuels by the hydroelectricity in Nepal. Using translog production function, this paper calculates the elasticity of substitution between hydroelectricity, coal, gas, petrol, diesel, and kerosene for the period of 1980 to 2016. Our findings suggest that all the fuels except kerosene are positively associated with economic growth during the study period, and the output elasticity of hydroelectricity is found be largest among these sources of energy. The findings also suggest that hydroelectricity has the potential for substitute other conventional fuels if the share of hydroelectricity is increased in the energy consumption composition. While there is not a huge variation in the elasticity of substitution between hydroelectricity and other fuels, the hydroelectricity has relatively higher potential to substitute coal followed by petrol, diesel, kerosene, and gas. The findings of the paper are supportive of the hypothesis that Nepal could potentially absorb the hydroelectricity generated in near future if incentive mechanisms are initiated that allow substitution of conventional fossil fuels by the hydroelectricity.
\end{abstract}

Key words: Inter-fuel substitution, Hydroelectricity, fossil fuel, translog production function, Ridge regression

JEL Code: O13, Q42, Q43

\section{BACKGROUND}

Energy is a key source of economic growth because many production and consumption activities involve energy as a basic input. The empirics suggest that higher energy consumption contributes to higher economic growth though reverse is also true (Kraft \& Kraft, 1978; Masih \& Masih, 1996;Asafu-Adjiye, 2000; Lee \& Chang, 2007; Narayan \& Smyth, 2008; Ozturk, 2010). The findings are in general applicable in both developed 
and developing countries though the extent of contribution and direction of causality may vary (Ozturk, 2010).

The important role of energy is also common in development economics literature. In addition to increased economic growth and economic growth dimension, the development economics literature views the energy from access, distribution, affordability and right perspective too (Zillman, Lucas \& Pring, 2002). For example, Sustainable Development Goal (SDG) seven acknowledges that the economic development of a country significantly depends on the long-term availability of energy from different sources that are affordable, accessible and environmentally friendly (UN, 2015). This is even more important for developing countries as the need for reliable and affordable form of energy is more fundamental; and reliable energy supports expansion of industry, helps modernizing agriculture, increases trade and improves transportation (Sari \& Soytas, 2007).

While the role of energy in economic growth and development is widely acknowledged and documented, there are issues about nature and type of energy used. About $80 \%$ of total energy consumption in the world is met through the fossil fuel (WB, 2018). Keeping the detrimental consequences of the consumption of dirty fuel to the environment and economy, there are concerns about sources of the fuels that meet the current energy demand. The conventional fossil fuels are the prime cause of carbon dioxide $\left(\mathrm{CO}_{2}\right)$ emissions in the globe (Meehl et al., 2007). Accordingly, using of these fossil fuels comes at greater cost; they seriously alter the ecosystem and human wellbeings in several ways. Further, the excessive dependence on selected countries for oil and volatility of oil price and market has forced many countries to look into the alternative source of energy (Marques et al., 2016).

These are the reasons the world is embarking towards an energy mix with increasing share of clean energy. Owing to high cost of fossil fuel to environment, ecology and economy, there are already initiatives taken towards energy generation from clean sources such as solar, wind, hydropower, and nuclear energy (Srirangan et al., 2012). Following the Paris agreement 2015 -- a legal binding agreement on climate change that aims to keep global warming below $2^{\circ} \mathrm{C}$ by $21^{\text {st }}$ century, countries like USA, Canada, Germany, France, are moving towards cleaner energy (Chang et al., 2015)The fastest growing economies like China, India, Brazil and other countries are also promoting the production and consumption of energy based on renewable resources (Green \& Stern, 2017; Nowtony et al., 2015).

In spite of huge renewable energy production potential, Nepal relies heavily on the petroleum product to fulfill its energy needs. While fuel woods still dominates the 
energy mix basket accounting as high as $71 \%$ compared to fossil fuels $16 \%$ and renewals at $1 \%$ (WECS, 2014), there is has been exponential increase in the consumption of fossil fuels- especially of the petroleum products (NRB, 2018). Accordingly, the import bills of petroleum products have been substantial. In FY 2017/18, about $29 \%$ of the total major imports were accounted by the import of petroleum product (NRB, 2018). This clearly has implication of external sector imbalance in addition to the environmental cost to the economy. Owing to huge potential of hydro electricity generation in Nepal, there is obvious question whether it will be able to substitute the conventional fossil fuels.

Despite that hydroelectricity is in short supply compared to demand in recent years, there has been moderate progress on the production of hydroelectricity. By the FY 2017/18, the installed capacity of the hydroelectricity has reached 1020 MW and government further wants to produce electricity in the coming years. The current demand for electricity during peak hours has been around 1250 MW with about 20 percent increment in the demand for electricity per annum (MOF, 2018). This would mean that demand for hydroelectricity would reach 3110 by fiscal year (FY) 2080/81. If the business as usual scenario prevails, then it can be anticipated an excess supply of hydroelectricity in coming years.

Therefore, it is imperative to increase consumption of electricity in the country and one way to address this problem is to allow substitution of fossil fuels such as coal, gas, petrol, diesel and kerosene which dominates energy consumption basket especially of industrial sector in Nepal. However, there is lack of empirical evidence about extent hydroelectricity could substitute the fuels as mentioned above. More so, use of standard economic theory on addressing this question of inter-fuel substitution is still missing. The available literature are largely qualitative in nature and among the quantitative analysis, use of trend analysis has been common. These are also examined from purely technical or engineering perspective and use of economic theories and rationales are often limited.

Against this backdrop, this paper aims to answer the question of inter-fuel substitution potential in Nepal. The objective of the paper is to explore a potential for interfuel substitution between the major energy sources namely coal, petrol, diesel, gas, kerosene and hydroelectricity for the period of 1980-2016. This paper is expected to provide evidence about extent of substitution between different sources of the fuels in Nepal. 


\section{SURVEY OF LITERATURE}

Examining relationship between energy use and its contribution to economic growth is well documented in both theory and empirics. Marques et al. (2016) have summarized the existing literature in terms of (i) Feedback hypothesis; (ii) growth hypothesis; (iii) neutrality hypothesis; and (iv) conservation hypothesis. The environmental and ecological models have induced to look into the inter-fuel substitution possibility between the different sources of fuels and between the different sectors of the economy.

The early literature has applied the neo-classical growth models where energy is taken as one of input among several other inputs (Masih \& Masih, 1996; Wolde-Rufael, 2005; Lee, 2006). This essentially is equivalent to test whether energy has been a determinant of economic growth. These set of literatures have used standard production functions such as Cobb Douglas, Constant Elasticity of Substitution and translog functions, andare based on the time series or panel data for cross country analysis (Ozturk et al., 2010). The empirical findings of these papers in general support a positive relationship between energy consumption and economic growth though the casual evidence is mixed. For example, Masish and Masih (1996), following the co-integration and error correction model, found that energy consumption has contributed to economic growth in India whereas the reverse was found significant in Indonesia, Pakistan, Malaysia, Philippines and Singapore. Asafu-Adjaye (2000) using similar econometric techniques found energy consumption has increased GDP in India and Indonesia; and two way relationship exists in Thailand and Philippine. The study of Narayan and Smyth (2008) conducted in G-7 countries found a causal relationship between energy consumption and economic growth. In similar fashion, Lee and Chang (2008) examining sixteen Asian countries and applying panel cointegration and panel ECM found energy consumption contribute to GDP in long run yet GDP boosts the energy consumption in the short run.

However, there were concerns that early write-ups on energy growth nexus fails to consider the other way implications to environment and ecosystem. While some of early literature tried to capture nonlinear nature of relationship between energy and economic growth following environmental Kuznets Curve (EKC) hypothesis, they failed to capture the nature-ecology-energy-growth nexus in fullest sense. The EKC hypothesis states that in early stage of economic development, the energy consumption increases along with economic growth, and for that matter increase in pollution, whereas after certain threshold energy consumption may not lead economic growth as later is used to clean the environment and therefore reduction in the energy (Ang, 2007; Lean \& Smyth, 2010). 
For these reasons, the recent literature uses environmental and ecological models to examine the energy consumption and economic activities. Kolstad and Kraukraemer (1993) noted that energy use (and resource use in general) might have negative consequences in long run though it may benefit the economy in the short run. They suggests for inclusion of a dynamic and interactive model compared to large empirical studies that are static in nature and miss the environment economy link aspects of the theoretical foundation. This appeal to consider a general equilibrium and dynamic framework to capture the causal and long run relationship between energy consumption and economic activities (Nordhaus, 1992; Jorgensen \& Wilcoxen, 1993). Keeping in view of type of energy use and its possible detrimental consequences to the economy, recent literature have focused on the energy economic growth nexus by separating the energy into renewable and non-renewable. Dogan (2015) and Bhattacharya et al. (2016) are the examples to this account.

It is in line with growth and conservation hypothesis; there is growing literature on use of energy mix and its implication to the economy. This apparently appeals for looking into the inter-fuel substitution. There have been a number of studies conducted for examining the inter-fuel substitution especially between the fossil fuel and renewable energy. For example, Ma et al. (2008) looked into the Chinese energy economy focusing on the technological change, factor demand and inter-fuel substitutability. Using time series data and applying translog cost function to estimate energy elasticity, the study shows that a change in an individual fuel price affects fuel consumption through the feedback effect between the inter-factor and inter-fuel substitution assuming that the production function is weakly separable in the major components of energy, capital, and labor. Stern (2012) documented the inter-fuel substitution possibilities of different sector by taking 47 sample studies. The study mainly focuses on substitution between coil, oil, gas, and electricity. This study shows that the industrial sector has significantly greater elasticity (more than unity) between coil-oil, oil-gas, oil-electricity, and gas-electricity whereas the elasticity between coil-gas, and coil-electricity are insignificantly different from unity or zero due to their large standard error.

Whereas there has been literature available in international context, there are limited national studies that examines the potential substitution between different sources of fuels. Few studies have explored the potential growth of the different sources of fuel, for example hydro and solar, yet the potential substitution has not been looked into. For example, K C et al. (2010) paper highlights the current status of energy consumption by different sectors (Residual sector 365.8 million GJ, Industrial sector 13.4 million GJ, commercial sector 5.1 million GJ, Transportation 20.9 million GJ, Agriculture sector 3.6 million GJ) in Nepal and elucidates the role of renewal energy. Adhikari, Gurung, 
and Bhattarai (2014) analyze the Solar Energy Potential in Nepal and Global Context. Recently, Joshi and Bohara (2017) examined household preferences for cooking fuels and inter-fuel substitution using household level data. The main objective of this research is to quantify the impacts of the household's economic and non-economic attributes (income, age, education, gender of household head, forest types and locations and media exposure). Since there is limited understanding about inter-fuel substitution in Nepal, this paper aims to bridge this gap. It also aims to initiate discussion on the possible fuel substation in Nepal in view of the huge potential of the renewable energy in general and hydroelectricity in particular.

\section{MODEL AND EMPIRICAL STRATEGY}

Since primary interest of the paper is to look into potential inter-fuel substitution, we follow standard translog production function approach to examine the relationship between different forms of energy namely hydroelectricity, coal, gas, petrol, diesel and kerosene and output measured by country's Gross Domestic Product (GDP). This will allow us to compute the elasticity of substitution- a parameter of primary interest in the paper. Whereas Constant Elasticity of Substitution (CES) and Cob-Douglas (C-D) production function are widely used in examining the input output relationship, a translog production function developed by Christensen et al. (1975) is preferred in computing elasticity of substitution. This function is preferred over others due to its strong theoretical rigor and flexibility of usage as it allows the researchers to avoid the need to specify a particular production function (Pollak et al., 1984;Stratopoulos et al., 2000).

Following the seminal work of Christensen et al. (1975) on translog production function, we too adopt a twice differentiable translog production function expressing gross output $(Q)$ as a function of combination of different inputs. The general form of the translog production function which is a second order Taylor Series approximation relating output as a function of combination of inputs is giving as follows (Christensen et al., 1975; Pavelescu, 2011):

$$
\ln Q_{t}=\beta_{0}+\frac{1}{2} \mathrm{O}_{i} \beta_{i} \ln X_{i t}+\mathrm{O}_{i} \mathrm{O}_{j} \beta_{i j} \ln X_{i t} \ln X_{j t}
$$

Where $Q_{t}$ represents output at time $t, \beta_{0}$ is the state of technical knowledge, $X_{\mathrm{it}}$ and $X_{\mathrm{jt}}$ respectively represent different unit of inputs $\mathrm{i}$ and $\mathrm{j}$ at each time $\mathrm{t}, \beta_{\mathrm{t}}$ and $\beta_{\mathrm{ij}}$ are the technologically determined parameter estimates. Pavelescu (2011) has argued that this functional form enables the researcher to circumvent the imposition of assumptions such as perfect substitution or competition among the factors of production. The existence of the exponential terms provides for nonlinearity between the inputs and 
the output. These features make the translog production function more appealing relative to other functional forms.

Specific to our case, the translog production function relates the gross output $(Q)$ as a function of capital stock $(K)$,labour $(L)$ and energy $(E)$. Here, energy $(E)$ represents different forms of the energy sources namely hydroelectricity, gas, coal, petrol, diesel and kerosene. Since E is composed of different fuel sources, it is essential to assume the function to be separable and homothetic in its fuel inputs. In a multivariate model with $n$ inputs, the number of estimable parameters equals $n(n+3) / 2$ if all inputs have translog components in the model thereby creating over parameterization as the number of parameters 'explode'. Thus, we include only the translog component of the variables that satisfy the objective of the study. While literature suggests for the inclusion of capital $(K)$ and Labour $(L)$, we have excluded them for two reasons. First, the data on labor for the study period in annual basis was not available. Second, the focus of our paper is the interfuel substitution rather than different forms of the input. Therefore, the production function for our purpose is specified as follows:

$$
\begin{aligned}
& \ln Q_{t}=\beta_{0}+\beta_{c} \ln C_{t}+\beta_{G} \ln G_{t}+\beta_{p} \ln p_{t}+\beta_{D} \ln D_{t}+\beta_{k} \ln K_{t}+\beta_{H} \ln H_{t}+\beta_{C G} \ln C_{t} \ln G_{t}+\beta_{C P} \ln C_{t} \ln P_{t}+ \\
& \beta_{C D} \ln C_{t} \ln D_{t}+\beta_{C K} \ln C_{t} \ln K_{t}+\beta_{C H} \ln C_{t} \ln H_{t}+\beta_{G P} \ln G_{t} \ln P_{t}+\beta_{G D} \ln G_{t} \ln D_{t}+\beta_{G K} \ln G_{t} \ln K_{t}+\beta_{G H} \ln G_{t} \ln H_{t}+ \\
& \beta_{P D} \ln P_{t} \ln D_{t}+\beta_{P K} \ln P_{t} \ln K_{t}+\beta_{P H} \ln P_{t} \ln H_{t}+\beta_{D K} \ln D_{t} \ln K_{t}+\beta_{D H} \ln D_{t} \ln H_{t}+\beta_{K H} \ln K_{t} \ln H_{t}+ \\
& \beta_{C C}\left(\ln C_{t}\right)^{2}+\beta_{G G}\left(\ln G_{t}\right)^{2}+\beta_{P P}\left(\ln P_{t}\right)^{2}+\beta_{D D}\left(\ln D_{t}\right)^{2}+\beta_{K K}\left(\ln K_{t}\right)^{2}+\beta_{H H}\left(\ln H_{t}\right)^{2} .
\end{aligned}
$$

where $\ln Q$ is the $\log$ of gross domestic product, $\ln C$ is the $\log$ of coal consumption, $\ln G$ is the $\log$ of gas consumption, $\operatorname{lnP}$ is the $\log$ of petrol consumption, $\operatorname{lnD}$ is the $\log$ of diesel, $\operatorname{lnK}$ is the log of kerosene and $\ln H$ is the log of hydroelectricity. The interactive and higher polynomial order terms correspond the specific fuel as identified above.

From equation (2), we can obtain the estimates of elasticity of substitution among the competing fuels used in the generation of electricity by first obtaining the estimates of the output elasticity of each of the inputs. Considering the economic region of a linearly homogenous production function which is characterized by strictly positive marginal productivities of all inputs, the output elasticity of an input $i$ is calculated as:

$\eta_{i t}=\frac{\partial \ln Q_{t}}{\partial \ln X_{i t}}=\beta_{i}+\sum_{j} \beta_{i j} \ln X_{j t}>0$

Thus, for each of the fuel inputs $\operatorname{Coal}(\mathrm{C}), \operatorname{Gas}(\mathrm{G}), \operatorname{Pertrol}(\mathrm{P})$, Diesel(D), Kerosene(K), Hydroelectricity $(\mathrm{H})$, the output elasticity is giving respectively as:

Coal: $\eta_{C t}=\frac{\partial \ln Q_{t}}{\partial \ln C_{t}}=\beta_{C}+\beta_{C G} \ln G_{t}+\beta_{C P} \ln P_{t}+\beta_{C D} \ln D_{t}+\beta_{C K} \ln k_{t}+\beta_{C H} \ln H_{t}+2 \beta_{C C} \ln C_{t} \ldots$ 
Gas: $\eta_{G t}=\frac{\partial \ln Q_{t}}{\partial \ln G_{t}}=\beta_{G}+\beta_{C G} \ln G_{t}+\beta_{P G} \ln P_{t}+\beta_{D G} \ln D_{t}+\beta_{K G} \ln k_{t}+\beta_{H G} \ln H_{t}+2 \beta_{G G} \ln G_{t}$

Petrol: $\eta_{P t}=\frac{\partial \ln Q_{t}}{\partial \ln P_{t}}=\beta_{P}+\beta_{C P} \ln C_{t}+\beta_{G P} \ln G_{t}+\beta_{P D} \ln D_{t}+\beta_{P K} \ln k_{t}+\beta_{P H} \ln H_{t}+2 \beta_{P P} \ln P_{t} \ldots$

Diesel: $\eta_{D t}=\frac{\partial \ln Q_{t}}{\partial \ln C_{t}}=\beta_{D}+\beta_{D C} \ln C_{t}+\beta_{G D} \ln G_{t}+\beta_{P D} \ln P_{t}+\beta_{K D} \ln k_{t}+\beta_{H D} \ln H_{t}+2 \beta_{D D} \ln D_{t}$

Kerosene: $\eta_{K t}=\frac{\partial \ln Q_{t}}{\partial \ln K_{t}}=\beta_{K}+\beta_{C K} \ln C_{t}+\beta_{K G} \ln G_{t}+\beta_{K P} \ln P_{t}+\beta_{K D} \ln D_{t}+\beta_{K H} \ln H_{t}+2 \beta_{K K} \ln K_{t}$

Hydropower: $\eta_{H t}=\frac{\partial \ln Q_{t}}{\partial \ln H_{t}}=\beta_{H}+\beta_{C H} \ln C_{t}+\beta_{H G} \ln G_{t}+\beta_{H P} \ln P_{t}+\beta_{H D} \ln D_{t}+\beta_{H K} \ln K_{t}+2 \beta_{H H} \ln H_{t} \ldots$

Where $\eta_{c t}, \eta_{G t}, \eta_{P t}, \eta_{D t}, \eta_{K t}, \eta_{H t}$ indicate outputs of elasticities of coal, gas, petrol, diesel, Kerosene, and hydropower respectively. From the estimates of the output elasticities, we can then obtain the elasticity of substitution among the computing fuels. The elasticity of substitution between two fuel inputs is expressed as the relative variation in the proportion of input factors to the percentage change in marginal rate of technical substitution of the inputs and it is calculated as

$\sigma_{i j}=\left[\frac{\left(M P_{j t} / M P_{i t}\right.}{\left(X_{i t} / X_{j t}\right)}\right] \cdot\left[\frac{d\left(X_{i t} / X_{j t}\right)}{d\left(M P_{j t} / M P_{i t}\right)}\right]$

After a mathematical derivation, the elasticity of substitution between two inputs $i$ and $j$ for $(i \neq j ;=C, G, P, D, K, H)$ are given as:

$$
\sigma_{i j}=\left[1+\frac{-\beta_{i j}+\left(\eta_{i} / \eta_{j}\right) \beta_{j j}}{-\eta_{i}+\eta_{j}}\right]^{-1}
$$

Thus the substitution elasticity between coal, gas, petrol, diesel, kerosene, and hydropower are calculated as:

$$
\begin{gathered}
\sigma_{C H}=\left[1+\frac{-\beta_{C H}+\left(\eta_{C} / \eta_{H}\right) \beta_{H H}}{-\eta_{C}+\eta_{H}}\right]^{-1} . \\
\sigma_{P H}=\left[1+\frac{-\beta_{P}+\left(\eta_{P} / \eta_{H}\right) \beta_{H H}}{-\eta_{P}+\eta_{H}}\right]^{-1} \cdots
\end{gathered}
$$


$\sigma_{D H}=\left[1+\frac{-\beta_{D H}+\left(\eta_{D} / \eta_{H}\right) \beta_{H H}}{-\eta_{C}+\eta_{D}}\right]^{-1}$

$\sigma_{K H}=\left[1+\frac{-\beta_{K H}+\left(\eta_{K} / \eta_{H}\right) \beta_{H H}}{-\eta_{K}+\eta_{H}}\right]^{-1}$

$\sigma_{G H}=\left[1+\frac{-\beta_{G H}+\left(\eta_{G} / \eta_{H}\right) \beta_{H H}}{-\eta_{G}+\eta_{H}}\right]^{-1}$

In the above equations $\sigma_{C H}, \sigma_{P H}, \sigma_{D H}, \sigma_{K H}$, and $\sigma_{G H}$ are respectively the substitution elasticities between coal and hydropower, petrol and hydropower, diesel and hydropower, kerosene and hydropower, and gas and hydropower.

However, it is worth to consider that the specification of the trans-log production with squared term of the some of the explanatory variables makes multicollinearity a suspect. This can lead to inaccurate estimates of the regression coefficients, inflate the standard errors of the regression coefficients, deflate the partial t-statics for the explanatory variables, give false nonsignificant $\mathrm{p}$-values and degrade the predictability of the model (Gujarati, 2009; Wooldridge, 2010). The use of conventional OLS thus becomes inappropriate in the face of severe multicollinearity. To check the presence multicollinearity in the model, variance inflation factors (VIFs) of each of the explanatory variables are computed. If VIFs are greater than 10 and the condition number of the Eigen values of correlations of some variables are greater than 100 conforming that multicollinearity is a severe problem thereby making the use of the OLS estimation procedure inappropriate (Gujarati, 2009).

To address the problem of multicollinearity, this study adopts the use of ridge regression procedure developed by Hoerl and Kennard (1970). In the presence of multicollinearity, OLS estimates are unbiased but their variances are too large so they may be far from the true value. Ridge regression involves the addition of a degree of bias, usually referred to as biasing constant (k), such that the standard errors are reduced. In ridge regression, the usual matrix of the OLS parameter estimate $B=\left(X^{\prime} X\right)^{-1} X^{\prime} Y$ is modified as $B_{R}=\left(X^{\prime} X+k I\right)^{-1} X^{\prime} Y$, where $\mathrm{k}$ is the ridge parameter or the biasing constant which satisfies the condition $0<\mathrm{k}<1$ and I is an identity matrix (Wooldridge, 2010). There usually exists a value of $k$ for which mean squared error of the ridge regression estimator is less than that of least squares estimators. Since $\mathrm{k}$ is a measure of biasness of the ridge regression, it is desirable to choose the smallest value of $k$ that minimizes the bias. This value of $\mathrm{k}$ referred to as the optimum $\mathrm{k}$ and it is determined 
with the use of a graph called ridge trace. The ridge trace plots the ridge regression coefficients as a function of $k$ and the value of $k$ for which the regression coefficients stabilize is chosen as the optimum (Hoerl and Kennard, 1970).

\section{DATA SOURCE AND DEFINITION OF VARIABLES}

This study relies on the secondary sources of data. Data published by Central Bureau of Statistics, Nepal Oil Corporation, International Energy Agency (IEA), Nepal Electricity Authority for the period of 1980 to 2016 are taken in the study. The definition and source of data used in the paper as summarized below.

Gross Domestic Product (GDP): GDP is the monetary value of final goods and services produced within country during an accounting period. GDP at basic price (measured in constant price) is taken as the dependent variable. This is taken from national income estimates of Central Bureau of Statistics, Government of Nepal.

Coal: Carbon is defined as a piece of glowing carbon or charred wood. In Nepal low to medium grade occurrences/deposits are known in four stratigraphic positionsQuaternary lignite, Siwalic coal, Eocene coal, Gondwana coal but are present in scattered amount in most of the areas. The figures on coal is taken from International Energy Agency.

Petrol: Petrol is a light fuel that is obtained by distilling petroleum and used in internal combustion engines. Petroleum formation occurs by various hydrocarbons combining with certain minerals such as sulphur under extreme pressure. This figure is obtained from Nepal Oil Corporation.

Diesel: Diesel fuel in general is any liquid fuel produced from various sources- the most common being petroleum. Other sources include biomass, animal fat, biogas, natural gas and coal liquefaction. Petroleum diesel, also called petro diesel, or fossil diesel is the most common type of diesel fuel. The figure in Diesel is obtained from Nepal Oil Corporation.

Kerosene: Kerosene is flammable hydrocarbon oil usually obtained by distillation of petroleum and used as a fuel, solvent, and thinner. Kerosene is used especially in jet engines of aircraft (jet fuel) and some rocket engines and is commonly used as a domestic cooking, lighting fuel and domestic heating boilers. The figures on Kerosene are collected from Nepal Oil Corporation.

Gas: Gas (also known as LPG) is a type of fuel consisting of hydrocarbon gases in liquid form. LPG or liquefied petroleum gas describes the flammable hydrocarbon gassed including propane, butane, and mixtures of these gasses. This is a staple source 
of energy for many residential homes and other industries as well as it come with a myriad of uses. The figures on Gas is also obtained from Nepal Oil Corporation.

Hydroelectricity: It is the energy produced from generators that are pushed by the movement of water. The rivers, dams, reservoir or collected water are the source for this power generation. The data of hydroelectricity are collected from Nepal Electricity Authority.

\section{RESULTS AND DISCUSSION}

We estimate a number of equations and later used the parameters to compute the elasticity of substitution between the variables of the interest. Figure 1, based on the Annex 1, reports the ridge regression results. Based on the ridge regression results, we then estimate the output elasticity of the different fuels, results of which are summarized in the Table 1. Table 2 summarizes the elasticity of substitution between the different inputs.

\section{Ridge Regression Results}

The results of the ridge regression are reported in the Annex 1. We first ran the OLS and perform a test to check the presence of multicollinearity in the result. The VIF suggested that multicollinearity is present in the OLS equation. Accordingly, we follow ridge regression method. For this, we ran a number of regressions based on the different values of $\mathrm{k}$ and finally choose 0.005 as the biasing constant for it as it is the point where parameters stabilize. The overall goodness of the models found good (Appendix 1). More importantly, the VIF has been reduced to significantly thus conforming that the ridge regression has been effectively deal with the problem of multicollinearity.

However, we could find only few coefficient statistically significant (Appendix 1). This is because of the higher number of explanatory variables and limited number of observations in our dataset. Since there was no alternative available in terms of data availability, we use this result owing to tradeoff between multicollinearity, number of observations and statistical significance of the parameters estimated. Hence, our results should be taken as indicative and further evidence are required.

Figure 1 plots the ridge trace for the ridge regression. We display a large range of values for $k$ on a logarithmic scale so that the points on the vertical axis which contains the points for the least squares solution where $k$ is zero may be seen. We see that adding $k$ changes the values of the coefficient and stabilize around the value 0.005 . 
Figure 1: Ridge Trace of the Regression Results

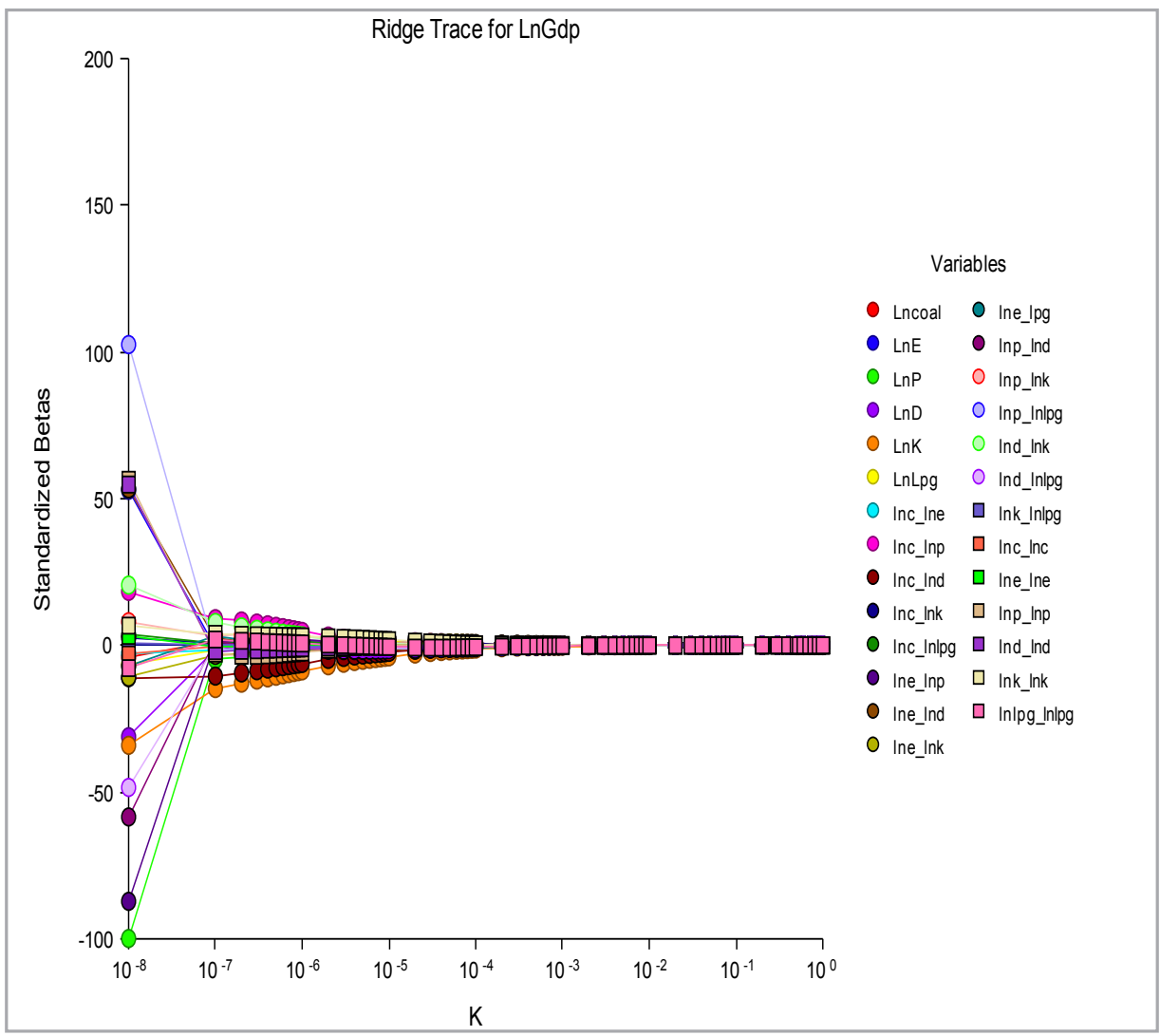

Source: Author's Computation

\section{Output Elasticity}

The parameter estimates of the ridge regression provide the platform to obtain the estimates of output elasticity of the fuels: Coal, Gas, Petrol, Diesel, Kerosene, Hydropower used in the generation of energy. Table 1 reports the output elasticity of different fuels. We find an average elasticity of coal, gas, petrol, diesel, kerosene and hydroelectricity as $0.028,0.024,0.026,0.047,-0.017$, and 0.367 respectively for the period of 1980-2017.The findings suggest that, except for early few years, the output elasticity of fuels other than kerosene is positive. This implies that the higher level of consumption of the fuels other than kerosene is positively associated with economic growth during the sample period. Kerosene is found negative which could be because it is mostly used for the consumption purpose without contributing the production of goods and services in the economy. 
Table 1: Output Elasticity of Different Fuels

\begin{tabular}{|c|c|c|c|c|c|c|}
\hline Year & Coal & Gas & Petrol & Diesel & Kerosene & Electricity \\
\hline 1980 & -0.016 & 0.02 & -0.0029 & 0.041 & -0.036 & 0.345 \\
\hline 1981 & -0.013 & 0.019 & -0.0041 & 0.04 & -0.036 & 0.334 \\
\hline 1982 & -0.012 & 0.019 & -0.004 & 0.041 & -0.035 & 0.34 \\
\hline 1983 & -0.006 & 0.02 & -0.0011 & 0.042 & -0.032 & 0.324 \\
\hline 1984 & -0.01 & 0.021 & 0.0005 & 0.043 & -0.032 & 0.339 \\
\hline 1985 & -0.009 & 0.021 & $2 \mathrm{E}-05$ & 0.042 & -0.032 & 0.332 \\
\hline 1986 & 0.0096 & 0.021 & 0.0126 & 0.043 & -0.028 & 0.364 \\
\hline 1987 & 0.0133 & 0.022 & 0.0172 & 0.044 & -0.025 & 0.373 \\
\hline 1988 & 0.014 & 0.022 & 0.0181 & 0.044 & -0.025 & 0.377 \\
\hline 1989 & 0.0153 & 0.022 & 0.0186 & 0.044 & -0.025 & 0.378 \\
\hline 1990 & 0.0307 & 0.02 & 0.0184 & 0.044 & -0.022 & 0.342 \\
\hline 1991 & 0.0245 & 0.022 & 0.0224 & 0.045 & -0.021 & 0.37 \\
\hline 1992 & 0.0234 & 0.023 & 0.0236 & 0.046 & -0.021 & 0.378 \\
\hline 1993 & 0.0278 & 0.023 & 0.0251 & 0.046 & -0.02 & 0.372 \\
\hline 1994 & 0.0267 & 0.024 & 0.0271 & 0.047 & -0.019 & 0.383 \\
\hline 1995 & 0.0289 & 0.024 & 0.0281 & 0.047 & -0.018 & 0.383 \\
\hline 1996 & 0.0304 & 0.025 & 0.0289 & 0.047 & -0.018 & 0.383 \\
\hline 1997 & 0.0311 & 0.025 & 0.0292 & 0.048 & -0.017 & 0.384 \\
\hline 1998 & 0.0277 & 0.026 & 0.0316 & 0.049 & -0.017 & 0.399 \\
\hline 1999 & 0.0292 & 0.027 & 0.0331 & 0.049 & -0.016 & 0.4 \\
\hline 2000 & 0.031 & 0.027 & 0.0339 & 0.05 & -0.014 & 0.397 \\
\hline 2001 & 0.0317 & 0.027 & 0.0348 & 0.05 & -0.014 & 0.399 \\
\hline 2002 & 0.0376 & 0.026 & 0.0342 & 0.05 & -0.013 & 0.382 \\
\hline 2003 & 0.0375 & 0.027 & 0.035 & 0.05 & -0.012 & 0.383 \\
\hline 2004 & 0.0396 & 0.026 & 0.0354 & 0.05 & -0.011 & 0.377 \\
\hline 2005 & 0.0381 & 0.027 & 0.0367 & 0.05 & -0.011 & 0.384 \\
\hline 2006 & 0.0429 & 0.026 & 0.0368 & 0.05 & -0.01 & 0.371 \\
\hline 2007 & 0.0425 & 0.027 & 0.0376 & 0.05 & -0.009 & 0.372 \\
\hline 2008 & 0.0432 & 0.026 & 0.0375 & 0.049 & -0.008 & 0.371 \\
\hline 2009 & 0.0464 & 0.026 & 0.039 & 0.05 & -0.006 & 0.364 \\
\hline 2010 & 0.0476 & 0.026 & 0.0397 & 0.05 & -0.005 & 0.363 \\
\hline 2011 & 0.0481 & 0.027 & 0.0414 & 0.05 & -0.004 & 0.365 \\
\hline 2012 & 0.049 & 0.026 & 0.0417 & 0.05 & -0.003 & 0.36 \\
\hline 2013 & 0.052 & 0.026 & 0.0426 & 0.05 & -0.002 & 0.353 \\
\hline 2014 & 0.056 & 0.026 & 0.0425 & 0.05 & $-8 \mathrm{E}-04$ & 0.344 \\
\hline 2015 & 0.0545 & 0.026 & 0.0423 & 0.049 & $-9 \mathrm{E}-04$ & 0.342 \\
\hline 2016 & 0.0627 & 0.026 & 0.0441 & 0.05 & 0.0017 & 0.333 \\
\hline Average & 0.0278 & 0.024 & 0.0264 & 0.047 & -0.017 & 0.367 \\
\hline
\end{tabular}

Source: Author's Computation 
The results of the estimation of the output of elasticity reveal some important points. It is found that hydro power has higher output of elasticity than each of the fossil fuels despite having the least percentage of the energy mix. This is a pointer to one of its attribute as a clean energy with positive impacts on the economy. Similarly the output elasticity of diesel is higher than that of other fuels. This is explained by the fact that for the majority of the sample period, diesel dominates the energy generation fuel mix. Likewise, although, coal and kerosene have lower output elasticity compared to other fossil fuels, neither of the two dominated the fuel mix and did not have the big impact on the economy as electricity and other fossil fuels. Further, positive output elasticity of fuels also indicates that economy can absorb the energy mix.

\section{Elasticity of Substitution}

Based on the Table 1we finally compute the elasticity of substitution between different fuels. The results are provided in Table 2 . We confine our results to hydroelectricity and other fuels as this is the primary interest of the paper. The result showed that all the inputs pair considered in the study have positive estimates of elasticity of substitution. The average estimates for the period shows that coal and hydro has substantial substitution possibilities with an estimated coefficient of 1.06. Likewise, the elasticity of substitution between petrol and hydro is 1.03, diesel and hydro 1.02 , kerosene and hydro 1.02, and gas and hydro as 1.01. These results reveal some important information.

First, the elasticity of substitution is found greater than unity in all cases. This implies that hydroelectricity and other forms of fuels are found substitute during the study period. Technically, this can be interpreted as the reduction in other fuels such that this reduction exceeds the increase in relative prices indicating that they are gross substitutes. Since the elasticity of substitution is greater than unity, it is more likely that the fossil fuels will be substituted and the swap over the other productscould take place more easily. In case, the elasticity of substitution is less than unity, relative demand for a fuel falls but by proportionately less than the relative rises in its price. This could have indicated that hydroelectricity and other fuels were gross complements and less potential for swapping or substitute the products.

Second, the coefficient of elasticity of substitution is increasing, though marginally, over the years especially for coal and petrol. For example, the coefficient of substitution between coal and hydro was 1.05 in 1980 which has increased to 1.08 in 2016. This could be explained by the increasing share of hydroelectricity in the energy consumption basket over the years. However the coefficient for diesel and gas has remained stagnant over the years. This could be partially explained by condition of short supply of electricity over demand meaning that the sectors that consume diesel and gas have not got enough electricity. However, this aspect needs further exploration. It also warrants an analysis on composition of diesel and gas consumption by sectors. Nevertheless, elasticity of substitution is greater than one indicating that diesel and gas could also be substituted if the supply side constraints are removed. 
Table 2: Elasticity of Substitution between Hydropower and Other Fossil Fuels

\begin{tabular}{|c|c|c|c|c|c|}
\hline Year & $\begin{array}{l}\text { Coal and } \\
\text { hydro }\end{array}$ & $\begin{array}{l}\text { Petrol and } \\
\text { Hydro }\end{array}$ & $\begin{array}{l}\text { Diesel and } \\
\text { Hydro }\end{array}$ & $\begin{array}{l}\text { Kerosene } \\
\text { and Hydro }\end{array}$ & $\begin{array}{l}\text { Gas and } \\
\text { Hydro }\end{array}$ \\
\hline 1980 & 1.05 & 1.02 & 1.02 & 1.02 & 1.01 \\
\hline 1981 & 1.05 & 1.02 & 1.02 & 1.02 & 1.01 \\
\hline 1982 & 1.05 & 1.02 & 1.02 & 1.02 & 1.01 \\
\hline 1983 & 1.05 & 1.02 & 1.02 & 1.02 & 1.01 \\
\hline 1984 & 1.05 & 1.02 & 1.02 & 1.02 & 1.01 \\
\hline 1985 & 1.05 & 1.02 & 1.02 & 1.02 & 1.01 \\
\hline 1986 & 1.05 & 1.02 & 1.02 & 1.02 & 1.01 \\
\hline 1987 & 1.05 & 1.02 & 1.02 & 1.02 & 1.01 \\
\hline 1988 & 1.05 & 1.02 & 1.02 & 1.02 & 1.01 \\
\hline 1989 & 1.05 & 1.02 & 1.02 & 1.02 & 1.01 \\
\hline 1990 & 1.06 & 1.03 & 1.02 & 1.02 & 1.01 \\
\hline 1991 & 1.06 & 1.02 & 1.02 & 1.02 & 1.01 \\
\hline 1992 & 1.05 & 1.02 & 1.02 & 1.02 & 1.01 \\
\hline 1993 & 1.06 & 1.03 & 1.02 & 1.02 & 1.01 \\
\hline 1994 & 1.05 & 1.02 & 1.02 & 1.02 & 1.01 \\
\hline 1995 & 1.05 & 1.03 & 1.02 & 1.02 & 1.01 \\
\hline 1996 & 1.06 & 1.03 & 1.02 & 1.02 & 1.01 \\
\hline 1997 & 1.06 & 1.03 & 1.02 & 1.02 & 1.01 \\
\hline 1998 & 1.05 & 1.02 & 1.02 & 1.02 & 1.01 \\
\hline 1999 & 1.05 & 1.02 & 1.02 & 1.02 & 1.01 \\
\hline 2000 & 1.05 & 1.03 & 1.02 & 1.02 & 1.01 \\
\hline 2001 & 1.05 & 1.03 & 1.02 & 1.02 & 1.01 \\
\hline 2002 & 1.06 & 1.03 & 1.02 & 1.02 & 1.01 \\
\hline 2003 & 1.06 & 1.03 & 1.02 & 1.02 & 1.01 \\
\hline 2004 & 1.06 & 1.03 & 1.02 & 1.02 & 1.01 \\
\hline 2005 & 1.06 & 1.03 & 1.02 & 1.02 & 1.01 \\
\hline 2006 & 1.06 & 1.03 & 1.02 & 1.02 & 1.01 \\
\hline 2007 & 1.06 & 1.03 & 1.02 & 1.02 & 1.01 \\
\hline 2008 & 1.06 & 1.03 & 1.02 & 1.02 & 1.01 \\
\hline 2009 & 1.06 & 1.03 & 1.02 & 1.02 & 1.01 \\
\hline 2010 & 1.07 & 1.03 & 1.02 & 1.02 & 1.01 \\
\hline 2011 & 1.07 & 1.03 & 1.02 & 1.02 & 1.01 \\
\hline 2012 & 1.07 & 1.03 & 1.02 & 1.02 & 1.01 \\
\hline 2013 & 1.07 & 1.03 & 1.02 & 1.02 & 1.01 \\
\hline 2014 & 1.07 & 1.03 & 1.02 & 1.02 & 1.01 \\
\hline 2015 & 1.07 & 1.03 & 1.02 & 1.02 & 1.01 \\
\hline 2016 & 1.08 & 1.04 & 1.02 & 1.03 & 1.01 \\
\hline Average & 1.06 & 1.03 & 1.02 & 1.02 & 1.01 \\
\hline
\end{tabular}

Source: Author's computation 
Third, the elasticity of substitution between coal and hydro is found relatively larger (1.06), though not significantly, followed substitution of petrol (1.03), diesel (1.02), kerosene (1.02) and gas (1.01). This would suggest that coal is more likely to get substituted compared to others. Whereas the share of coal on energy consumption composition is just about $4 \%$, the recent trend reveals that the industries that were historically using coal are surging. The cement and brick kilns could be taken as example. It is therefore high potential that these industries could switch to hydroelectricity for their power consumption. In case of petrol, the vehicles consume the significant proportion. The results are supportive of the fact that use of electric vehicles can be promoted in place of combustion engine type vehicles. As discussed above, the diesel could have more potential to get substituted but owning to limited supply of the electricity, this has not taken place. Similar case exists in case of Gas.

Fourth, combined with the result from Table 1, it is found that the hydroelectricity has higher contribution to economic growth. With elasticity of substitution greater than unity along with high output elasticity of hydroelectricity, our result would mean that it could contribute to economic growth while substituting the fossil fuels. However, we do not attempt to establish the casual relationship between energy growth nexus, therefore, these results should be taken as indicative of the fact that hydroelectricity could be supportive for achieving the goals of higher economic growth in the country.

\section{CONCLUSION}

Given huge hydro potential in Nepal, it is crucial to examine to what extent the hydro electricity can substitute the conventional fossil fuels in Nepal. This paper examines the potential substitution between major sources of energy namely coal, petrol, diesel, gas, kerosene and hydroelectricity. Applying a translog production function and using the data for the period of 1980-2017, we estimate the elasticity of substitution between the different fuels. A ridge regression approach has been followed to avoid the multicollinarity issue in the estimation. Our finding suggests that hydroelectricity has the potential to substitute the fossil fuels currently being consumed in Nepal. We also find the elasticity of substitution is increasing over the years owing to increasing share of hydroelectricity in energy consumption composition during the same period. This would mean that hydroelectricity has potential to substitute other fuels if share of hydroelectricity in energy consumption composition is increased. While this paper has initiated to examine the inter-fuel substitution possibility in Nepal and given that our results owe some limitations, we suggest for further research on this field applying the different models and econometrics tools so as to find more robust evidence.

Authors would like to thank anonymous referee for helpful comments and suggestions on the paper. 


\section{Appendix 1}

Ridge Regression Results (Ridge Coefficient for $\mathrm{k}=0.005$ )

\begin{tabular}{|c|c|c|c|}
\hline $\begin{array}{l}\text { Independent } \\
\text { Variable } \\
\end{array}$ & $\begin{array}{l}\text { Regression } \\
\text { Coefficient }\end{array}$ & $\begin{array}{l}\text { Standard } \\
\text { Error } \\
\end{array}$ & VIF \\
\hline Intercept & 12.5135 & & \\
\hline Lncoal & 0.0056 & 0.0524 & 7.5165 \\
\hline LnE & 0.0499 & 0.0648 & 7.1414 \\
\hline LnP & 0.0073 & 0.0228 & 4.8736 \\
\hline LnD & 0.0292 & 0.0374 & 3.6119 \\
\hline LnK & -0.0221 & 0.0244 & 2.0034 \\
\hline LnLpg & 0.0140 & 0.0366 & 4.5307 \\
\hline lnc_lne & 0.0055 & 0.0183 & 16.7991 \\
\hline lnc_lnp & 0.0009 & 0.0021 & 4.0983 \\
\hline lnc_lnd & 0.0000 & 0.0016 & 1.8803 \\
\hline lnc_lnk & 0.0021 & 0.0052 & 11.2841 \\
\hline lnc_lnlpg & -0.0003 & 0.0042 & 11.0281 \\
\hline lne_lnp & 0.0061 & 0.0048 & 4.7445 \\
\hline lne_lnd & 0.0028 & 0.0045 & 5.5119 \\
\hline lne_lnk & 0.0064 & 0.0076 & 11.6864 \\
\hline lne_lpg & 0.0023 & 0.0047 & 4.8641 \\
\hline lnp_lnd & 0.0004 & 0.0008 & 1.6011 \\
\hline lnp_lnk & 0.0010 & 0.0020 & 5.0036 \\
\hline lnp_lnlpg & 0.0003 & 0.0010 & 2.5836 \\
\hline lnd_lnk & 0.0012 & 0.0031 & 5.2317 \\
\hline lnd_lnlpg & 0.0004 & 0.0014 & 2.7414 \\
\hline lnk_lnlpg & 0.0023 & 0.0043 & 5.4824 \\
\hline lnc_lnc & -0.0022 & 0.0100 & 26.3319 \\
\hline lne_lne & 0.0757 & 0.1327 & 21.6436 \\
\hline $\operatorname{lnp} \_\ln p$ & 0.0010 & 0.0012 & 5.4993 \\
\hline lnd_lnd & 0.0007 & 0.0016 & 3.9202 \\
\hline lnk_lnk & -0.0008 & 0.0033 & 18.9937 \\
\hline lnlpg_lnlpg & -0.0002 & 0.0014 & 3.0943 \\
\hline $\mathrm{R} 2=0.9632 \mathrm{~F}=20.006(0.0041)$ & & & \\
\hline
\end{tabular}




\section{References}

Adhikari, K. R., Gurung, S., \&Bhattarai, B. K. (2013). Solar energy potential in Nepal and global context. Journal of the Institute of Engineering, 9(1), 95-106.

Ang, J. B. (2007). CO2 emissions, energy consumption, and output in France. Energy policy, 35, 4772-4778.

Anup, K. C., Poudel, G., Poudel, S., \&Khadka, M. (2010, February). Hydro home systeman inventory on rural electrification. In 2010 The 2 nd International Conference on Computer and Automation Engineering (ICCAE), 5, 338-341). IEEE.

Asafu-Adjaye, J. (2000). The relationship between energy consumption, energy prices and economic growth: time series evidence from Asian developing countries. Energy economics, 22, 615-625.

Bhattacharya, M., Paramati, S. R., Ozturk, I., \& Bhattacharya, S. (2016). The effect of renewable energy consumption on economic growth: Evidence from top 38 countries. Applied Energy, 162, 733-741.

Chang, T., Gupta, R., Inglesi-Lotz, R., Simo-Kengne, B., Smithers, D., \& Trembling, A. (2015). Renewable energy and growth: Evidence from heterogeneous panel of G7 countries using Granger causality. Renewable and Sustainable Energy Reviews, 52, 1405-1412.

Christensen, L. R., Jorgenson, D. W., \& Lau, L. J. (1975). Transcendental logarithmic utility functions. The American Economic Review, 65, 367-383.

Costantini, V., Gracceva, F., Markandya, A., \&Vicini, G. (2007). Security of energy supply: Comparing scenarios from a European perspective. Energy policy, 35, 210-226.

Dogan, E. (2015). The relationship between economic growth and electricity consumption from renewable and non-renewable sources: A study of Turkey. Renewable and Sustainable Energy Reviews, 52, 534-546.

Green, F., \& Stern, N. (2017). China's changing economy: Implications for its carbon dioxide emissions. Climate Policy, 17, 423-442.

Gujarati, D. N. (2009). Basic econometrics. Tata McGraw-Hill Education.

Hoerl, A. E., \& Kennard, R. W. (1970). Ridge regression: Biased estimation for nonorthogonal problems. Technometrics, 12(1), 55-67. 
Kolstad, C. D., \& Kraukraemer, J. A. (1993). Natural resource use and the environment. In A.V. Kneese and J.L. Sweeney (Eds.), Handbook of natural resource and energy economics, Vol. III, (pp.1219-1266).North Holland: Elsevier

Kraft, J., \& Kraft, A. (1978). On the relationship between energy and GNP. The Journal of Energy and Development, 3, 401-403.

Jorgensen, D. W., \& Wilcoxen, P. J. (1993). Reducing US carbon dioxide emissions: An assessment of alternative instruments. Journal of Policy Modeling, 15, 491-520.

Joshi, J., \& Bohara, A. K. (2017). Household preferences for cooking fuels and inter-fuel substitutions: Unlocking the modern fuels in the Nepalese household. Energy Policy, 107, 507-523.

Lean, H. H., \& Smyth, R. (2010). $\mathrm{CO}_{2}$ emissions, electricity consumption and output in ASEAN. Applied Energy, 87, 1858-1864.

Lee, C. C. (2006). The causality relationship between energy consumption and GDP in G-11 countries revisited. Energy policy, 34, 1086-1093.

Lee, C. C., \& Chang, C. P. (2007). Energy consumption and GDP revisited: A panel analysis of developed and developing countries. Energy economics, 29, 12061223 .

Ma, H., Oxley, L., Gibson, J., \& Kim, B. (2008). China's energy economy: Technical change, factor demand and inter-factor/inter-fuel substitution. Energy Economics, 30, 2167-2183.

Marques, A. C., Fuinhas, J. A., \& Nunes, A. R. (2016). Electricity generation mix and economic growth: What role is being played by nuclear sources and carbon dioxide emissions in France? Energy Policy, 92, 7-19.

Masih, A. M., \& Masih, R. (1996). Energy consumption, real income and temporal causality: results from a multi-country study based on cointegration and error-correction modelling techniques. Energy economics, 18, 165-183.

Meehl, G. A., Stocker, T. F., Collins, W. D., Friedlingstein, P., Gaye, T., Gregory, J. M., ...\&Zhao, Z.-C. (2007). Global climate projections. In S. Solomon, D.Qin,M. Manning, M. Marquis, K. Averyt, M. M.B. Tingor, ...,\& Z. Chen (Eds.), Climate change 2007:The physical science basis(pp.747-846). Cambridge I New York: Cambridge University Press.

MOF. (2018). Economic survey 2017/18. Kathmandu: Ministry of Finance. Government of Nepal. 
Narayan, P. K., \& Smyth, R. (2008). Energy consumption and real GDP in G7 countries: New evidence from panel cointegration with structural breaks. Energy Economics, 30, 2331-2341.

Nordhaus, W. D. (1992). An optimal transition path for controlling greenhouse gases. Science, 258(5086), 1315-1319.

Nowotny, J., Dodson, J., Fiechter, S., Gür, T. M., Kennedy, B., Macyk, W., ...\& Rahman, K. A. (2018). Towards global sustainability: Education on environmentally clean energy technologies. Renewable and Sustainable Energy Reviews, 81, 25412551.

NRB (2018). Macro indicators of Nepal. Kathmandu: Nepal Rastra Bank.

Ozturk, I. (2010). A literature survey on energy-growth nexus. Energy policy, 38, 340349.

Pavelescu, F. M. (2011). Some aspects of the translog production function estimation. Romanian Journal of Economics, 32(1(41)), 131-150. Accessed from http://www.revecon.ro/articles/2011-1/2011-1-8.pdf

Pollak, R. A., Sickles, R. C., \& Wales, T. J. (1984). The CES-Translog: Specification and estimation of a new cost function. The Review of Economics and Statistics, 66, 602-607.

Sari, R., \& Soytas, U. (2007). The growth of income and energy consumption in six developing countries. Energy Policy, 35, 889-898.

Srirangan, K., Akawi, L., Moo-Young, M., \& Chou, C. P. (2012). Towards sustainable production of clean energy carriers from biomass resources. Applied Energy, 100, 172-186.

Stern, D. I. (2012). Interfuel substitution: a meta-analysis. Journal of Economic Surveys, 26, 307-331.

Stratopoulos, T., Charos, E., \&Chaston, K. (2000). A translog estimation of the average cost function of the steel industry with financial accounting data. International Advances in Economic Research, 6, 271-286.

UN,UN General Assembly (2015). Transforming our world: The 2030 agenda for sustainable development, 21 October 2015, A/RES/70/1.Accessed from: https://www. refworld.org/docid/57b6e3e44.html [accessed 03 June 2019].

WB. (2018). World development indicators 2018. Retrieved from https://data.worldbank. org/indicator/eg.use.comm.fo.zs [accessed 07 June, 2019]. 
WECS. (2014). Electricity demand forecast report. Kathmandu: Water and Energy Commission Secretariat, Government of Nepal.

Wolde-Rufael, Y. (2005). Energy demand and economic growth: The African experience. Journal of Policy Modeling, 27, 891-903.

Wooldridge, J. M. (2010). Econometric analysis of cross section and panel data, $2 n d$ ed. Cambridge: MIT Press.

Zillman, D. M., Lucas, A.\& Pring, G. (Eds.).(2002). Human rights in natural resource development: Public participation in the sustainable development of mining and energy resources. Oxford: Oxford University Press. 